\title{
Jovens brasileiros, consciência histórica e vida prática
}

\section{Young Brazilians, historical consciousness and practical life}

Maria Auxiliadora Schmidt*

\section{RESUMO}

O trabalho tem como objetivo analisar a relação entre a formação da consciência histórica e a vida prática de jovens, a partir da interpretação dos significados que determinados acontecimentos, como as manifestações de rua, têm nesse processo, particularmente quando estas manifestações têm como horizonte reivindicações de direitos básicos relacionados à vida prática dos sujeitos. Optou-se pela metodologia da pesquisa de cunho qualitativo, recortada a partir do estudo de um caso específico de um grupo de jovens estudantes de Curitiba. Resultados permitem afirmar que conhecer elementos da consciência histórica dos jovens, bem como fazer uma avaliação preliminar de formas de atuação de sua consciência histórica em relação às demandas da vida prática, pode ser um dos pressupostos metodológicos para o ensino de história.

Palavras-chave: consciência histórica; educação histórica; jovens e ensino de história.

\section{Abstract}

The paper aims to examine the relationship between the formation of historical consciousness and practical life among young people, from the interpretation of the meanings of certain events, such as street demonstrations, in this process, particularly when these manifestations show the claims for basic rights related to the practical life of the young people. We opted for the qualitative methodology research from the study of a specific case of a group of young students in Curitiba, Paraná. Results allow to say that to know elements of the historical consciousness of the young, as well as to make a preliminary assessment of performance of its historical consciousness in relation to the demands of practical life, can be one of the preconditions for History teaching.

Keywords: historical consciousness; historical education; young people and History teaching.

\footnotetext{
* Doutora em História. Professora associada da Universidade Federal do Paraná (UFPR), Programa de Pós-Graduação em Educação. Coordena o Laboratório de Pesquisa em Educação Histórica (LAPEDUH). Curitiba, PR, Brasil. dolinha08@uol.com.br
} 
Este trabalho se insere, de forma específica, no domínio de investigações que vem sendo denominado Educação Histórica, ${ }^{1}$ constitutivo da área do ensino de História, e cujo foco são, principalmente, pesquisas relacionadas com análise de ideias históricas e consciência histórica dos sujeitos. Neste particular, uma das questões pertinentes às preocupações do campo da Educação Histórica tem sido investigar possíveis relações existentes entre a vida prática dos jovens e as suas ideias históricas. Assim, cabe elucidar o conceito de vida prática e seu significado para a aprendizagem histórica. ${ }^{2}$ No âmbito da teoria da consciência histórica (Rüsen, 2001; Lee, 2006) há uma interlocução orgânica entre a ciência da história e a vida prática, e é nesta última que são produzidas e detectadas as carências e interesses que podem ser explicitados pelas ideias, métodos e formas de representação da disciplina História. É também à vida prática que o conhecimento histórico retorna a cumprir sua função de orientação temporal. Essa interlocução produz-se e reproduz-se na e pela cultura histórica.

Segundo Rüsen (2009), a cultura histórica é uma categoria de análise que permite compreender a produção e usos da história no espaço público na sociedade atual. Trata-se de um fenômeno do qual fazem parte o grande boom da História, o sucesso que os debates acadêmicos têm tido fora do círculo de especialistas e a grande sensibilidade do público em face do uso de argumentos históricos para fins políticos. Desse processo fazem parte também os embates, enfrentamentos e aproximações entre a investigação acadêmica, o ensino escolar, a conservação dos monumentos, os museus e outras instituições, em torno de uma aproximação comum do passado. Assim, para Rüsen (2009), a cultura histórica articula os diferentes elementos e estratégias da investigação acadêmica, da estética, da política, do lazer, da educação escolar e não escolar e de outros procedimentos da memória histórica pública. Segundo esse autor, "ela é quintessência das atividades e instituições sociais, pelas quais e nas quais acontece a consciência histórica" (Rüsen, 2014, p.101). Isto é, no âmbito da cultura histórica da qual faz parte a vida prática é que acontecem os modos de atuação da consciência histórica. Nessa direção, a categoria da cultura histórica teorizada por Rüsen aponta a consciência histórica como uma realidade elementar e geral da explicação humana do mundo e de si mesmo, com um significado inquestionável prático para a vida, propondo que da consciência histórica há somente um pequeno passo à cultura histórica. Se se examina o 
papel que tem a consciência histórica na vida de uma sociedade, ela aparece como uma contribuição cultural fundamentalmente específica que afeta e influi em quase todas as áreas da práxis da vida humana. Assim, a cultura histórica pode ser definida como a articulação prática e operante da consciência histórica na vida de uma sociedade. Como práxis da consciência tem a ver, fundamentalmente, com a subjetividade humana, como uma atividade da consciência pela qual a subjetividade humana se realizada na prática, cria-se, por assim dizer (Rüsen, 2009,p.4).

Na perspectiva rüseniana, a relação intrínseca entre consciência histórica e vida prática remete, necessariamente, à compreensão de como a ação humana no presente está matizada pelas determinações das diferentes dimensões da cultura histórica: a dimensão cognitiva, estética, política, ética e moral, dependendo da abrangência dessas dimensões na formação da consciência histórica dos agentes. Assim, uma análise da relação entre a formação da consciência histórica e a vida prática de jovens pode levar em consideração o significado que têm determinados acontecimentos, como as manifestações de rua, nesse processo, particularmente quando estas manifestações têm como horizonte reivindicações de direitos básicos relacionados à vida prática dos sujeitos. ${ }^{3}$

\section{MANifestaÇões DE RUA ${ }^{4}$ E VIDA PRÁtica dos JOVENS}

As manifestações de rua que ocorreram no Brasil em junho de 2013 fazem parte do conjunto de manifestações que vêm acontecendo desde 2011 em vários países do mundo. Apesar de suas peculiaridades, essas manifestações apresentam formas de luta semelhantes e consciência de solidariedade mútua, particularmente sob forma de uma catarse política protagonizada pela juventude, ocorrendo

uma sincronia cosmopolita febril e viral com uma sequência de rebeliões quase espontâneas surgidas na margem sul do Mediterrâneo e que logo se manifestaram na Espanha, com os Indignados da Puerta del Sol, em Portugal, com a Geração à Rasca, e na Grécia, com a ocupação da praça Syntagma. Em todos os países houve uma mesma forma de ação: ocupação de praças, uso de redes de comunicação alternativas e articulações políticas que recusavam o espaço institucional tradicional. (Carneiro, 2013, p.8) 
O filósofo Michael Löwy entende que a presença dos jovens nas diferentes manifestações contemporâneas é fruto de um sentimento de injustiça e insatisfação que existe na sociedade e os jovens são os primeiros a se organizar e protestar porque eles são mais influenciados pela indignação com a ordem das coisas no mundo,

o começo de qualquer movimento ou mudança social sempre se dá com um estado de espírito indignado, a começar na juventude. É fácil de entender o porquê de tanta indignação. Estamos numa situação em que a ordem social parece cada vez mais irracional, promovendo desigualdades gritantes, promovendo os excessos do mercado financeiro, a destruição do meio ambiente. (Löwy, 2011, p.14)

Em uma sociedade na qual a representação política está nas mãos de setores mais tradicionais, os jovens não se sentem representados e manifestam grande desconfiança em relação aos partidos e instituições políticas existentes. Ademais, decepcionados com as formas de protesto tradicionais, os jovens buscam novas formas de organização como a comunicação através dos meios eletrônicos, como o Facebook e o Twitter, que permitem uma mobilização mais rápida.

Apesar de semelhanças com os movimentos de outros países, o junho brasileiro de 2013 teve características próprias, podendo ser considerado uma insurgência democrática em favor do reconhecimento de novas identidades sociais e de direitos de participação na vida pública, pela juventude. Nesse movimento, vários fatores se entrelaçaram durante as semanas que trouxeram perplexidade à sociedade brasileira. Do início até meados de junho de 2013 houve várias manifestações com reivindicações claras: contra o aumento das passagens dos transportes públicos, liderada pelo MPL (Movimento Passe Livre) e contra os gastos com a Copa do Mundo a ser realizada em 2014 no Brasil. No dia 13 de junho, a forte repressão policial que ocorreu em diferentes cidades brasileiras despertou uma empatia em grande parte da população, que se transformou em desejo de participação, e a oportunidade de tomar as ruas aparecia como uma maneira de afirmar o direito à manifestação e à liberdade de expressão.

O slogan "Vem pra rua, vem" cuja apropriação por uma campanha publicitária gerou controvérsias nos meios de comunicação, tornou-se a palavra de ordem dos jovens. Como afirma Brant, foi a "sensação de tomar a história nas 
mãos e de gritar para ser ouvido que levou a população às ruas" (Brant, 2014, p.34). E os gritos foram representados em palavras contra a corrupção, em defesa da saúde e da educação pública de qualidade, como no slogan "Queremos educação e saúde padrão FIFA", numa alusão às exigências que a Federação Internacional de Futebol (FIFA) estava fazendo com relação à qualidade dos estádios de futebol brasileiros. Do dia 14 até 21 de junho, a esses temas se somou um discurso cívico, representado pela afirmação dos símbolos nacionais, particularmente a bandeira brasileira, utilizada como representação da afirmação das diferentes identidades presentes nas manifestações, nas quais uma das ausências mais expressiva foi a da representação dos grandes partidos políticos, além das reinvindicações de cunho econômico. Como afirma Brant, “é notável, por exemplo, que as questões econômicas que deflagraram manifestações em outros países tenham ficado de fora da pauta no Brasil. De maneira geral, a situação econômica era boa, a democracia predominava, o que torna ainda mais surpreendente o volume que as manifestações ganharam" (Brant, 2014, p.35).

Segundo sociólogos brasileiros, a juventude que participou dessas manifestações pode ser considerada, em sua maioria, como "os filhos da geração inserida”, os mais de 40 milhões de brasileiros que passaram a ter poder de consumo e cobram mais direitos:

Os adolescentes crescem com acesso ao consumo e a um volume de informações inédito por conta da internet. $\mathrm{E}$ a elite continua presa às categorias do passado. Tivemos mudanças na economia, mas não alteramos a nossa mentalidade. Um exemplo são os jovens dos rolezinhos, que não acionam os partidos políticos, mas agem politicamente ao invadirem os templos de consumo, antes vedados a eles. Esses adolescentes vindos das comunidades não são vistos como legítimos em alguns espaços. A elite reage horrorizada aos rolezinhos, que são apenas a entrada dos jovens das periferias urbanas nos shoppings. (Jardim, 2014, p.28)

Entende-se, dessa forma, que buscar conhecer a consciência histórica dos jovens pode ser uma forma de ouvir o que eles têm a dizer e também procurar entender como, da juventude, pode estar nascendo uma reinvenção da categoria política. 


\section{Percurso Metodológico}

O presente trabalho se anuncia como um estudo exploratório, com a finalidade de delimitar melhor o objeto de investigação e afinar instrumentos de pesquisa para futuros estudos que tomem a problemática da relação consciência histórica e vida prática de jovens como temática de pesquisa. Optou-se pela metodologia da pesquisa de cunho qualitativo, recortada a partir do estudo de um caso específico. Trata-se de um grupo de jovens estudantes de uma escola secundária pública, localizada na periferia da cidade de Curitiba, Paraná. Essa escola tem cerca de 930 alunos, distribuídos entre o $6^{\circ}$ e o $9^{\circ}$ ano do ensino fundamental e os 3 anos do ensino médio. $\mathrm{O}$ ensino fundamental funciona nos períodos da manhã e tarde e o ensino médio, no período noturno. A investigação foi realizada durante o mês de abril de 2014, em uma classe com 38 alunos do $3^{\circ}$ ano e outra com 20 alunos do $1^{\circ}$ ano do ensino médio noturno, o que aponta uma das características dos alunos investigados, o fato de serem alunos trabalhadores, na faixa etária entre 16 e 22 anos. Esses alunos trabalham, principalmente, em atividades de prestação de serviços, tais como atendentes de supermercados, ajudantes de obras na construção civil e também no ramo da informática.

Tabela 1 - Identificação dos sujeitos da investigação

\begin{tabular}{c|c|c}
\hline Idade & $\begin{array}{c}\text { Número de alunos: } \\
3^{\circ} \text { ano do Ensino Médio }\end{array}$ & $\begin{array}{c}\text { Número de alunos: } \\
1^{\circ} \text { ano do Ensino Médio }\end{array}$ \\
\hline 22 & 1 & - \\
21 & 3 & - \\
19 & 1 & 2 \\
18 & 6 & - \\
17 & 7 & 5 \\
16 & 14 & 11 \\
15 & - & 5 \\
\hline
\end{tabular}

Fonte: preparado pela autora (2014). 
O instrumento de investigação foi aplicado pelo professor da turma e tinha uma abertura com os seguintes dizeres:

Caro jovem, estamos realizando uma pesquisa sobre como os jovens de vários países estão compreendendo as manifestações e os conflitos que elas têm produzido. A nossa parte é saber como os jovens brasileiros pensam isso. E escolhemos você para dar sua opinião. Agradecemos muito a sua colaboração para a nossa pesquisa.

A primeira parte do instrumento, com questões fechadas, constava de perguntas sobre a identificação do jovem, uma questão sobre sua participação em manifestações e uma indagação sobre o que ele achava do conhecimento histórico: “Acha importante aprender História para...”. O objetivo principal era detectar a relação dos jovens com a participação nas manifestações e o que significava, para ele, aprender História.

Tabela 2 - Relação dos jovens com a participação nas manifestações

\begin{tabular}{c|c}
\hline Participa & 7 \\
Não participa & 46 \\
Não respondeu & 1 \\
\hline Total & 54 \\
\hline
\end{tabular}

Fonte: preparado pelas autoras (2014).

É importante destacar que alguns jovens complementaram suas respostas com algumas considerações:

- Não participei pois meus pais não deixaram, gostaria muito de ter participado, mas eles disseram que poderia ter tumulto e poderiam me machucar. ( $3^{\circ}$ ano, 16 anos)

- Não participei porque tenho que trabalhar. ( $3^{\circ}$ ano, 18 anos)

- Não tive chance, mas gostaria. ( $1^{\circ}$ ano, 14 anos)

- Não participei, mas participarei. (1 ${ }^{\circ}$ ano, 14 anos)

As considerações apresentadas são indiciárias de que, mesmo respondendo que não participaram, alguns jovens tinham ou têm intenções de participar de manifestações. 
Há também evidências de que o fato de não terem participado das manifestações não impediu que, em suas narrativas, os jovens apresentassem opiniões favoráveis à sua realização. Apenas um, entre os 58 jovens participantes, apresentou de maneira explícita em sua narrativa uma indiferença à realização de manifestações, afirmando que

- Não estou nem aí para as manifestações, mas gosto que as passagens baixem. ( $1^{\circ}$ ano, 14 anos)

Com relação à pergunta "Para você, aprender História é importante para...", os resultados mostraram um equilíbrio entre aqueles que respaldam a importância da aprendizagem no conhecimento do passado pelo passado, do passado para interpretar o presente, para interpretar o presente e projetar o futuro, para interpretar a mudança e a importância de se conhecer o passado para trazer exemplos para o presente e o futuro.

Tabela 3 - Significados da aprendizagem histórica para os jovens

\begin{tabular}{|c|c|}
\hline Significado da História & Número \\
\hline Estudo do passado pelo passado & 12 \\
\hline Estudo do passado para entender o presente & 9 \\
\hline Estudo do passado para explicar a origem e evolução & 5 \\
\hline $\begin{array}{l}\text { Estudo do passado para explicar as mudanças do presente. } \\
\text { Exemplo: Para lembrar o passado que foi muito difícil e refletir sobre } \\
\text { as mudanças que aconteceram no decorrer do tempo. (sem } \\
\text { identificação) }\end{array}$ & 7 \\
\hline Estudo do passado para tirar exemplos para o presente & 9 \\
\hline $\begin{array}{l}\text { Estudo da relação passado/presente e futuro para entender a mudança } \\
\text { e orientar a ação. }\end{array}$ & \\
\hline $\begin{array}{l}\text { Exemplo: Entender toda a garra de nossos antepassados para seguir } \\
\text { lutando para que lá na frente a gente tenha feito pelo menos um } \\
\text { pouco de diferença. (16 anos, } 3^{\circ} \text { ano) }\end{array}$ & 7 \\
\hline Sem nexo ou não responderam & 9 \\
\hline
\end{tabular}

Fonte: as autoras (2014). 
Há que destacar o fato de que 12 jovens responderam que aprendem história para conhecer o passado pelo passado. Trata-se de algo relevante e a ser considerado, já que estes jovens estudaram história em todos os anos do Ensino Fundamental. Havia uma expectativa de que eles pudessem atribuir algum significado à relação passado, presente e futuro pois, "antes mesmo que o passado seja abordado no modo típico de uma disciplina especializada, elaborado pela pesquisa e tornado presente pela historiografia, ele é sempre atual nos contextos da vida prática atual" (Rüsen, 2015, p.37). Uma das inferências a serem feitas é a de que na perspectiva da orientação temporal no fluxo do tempo o "presentismo" não se destaca como expressão da consciência histórica desse grupo de jovens. Observa-se um equilíbrio na presença de uma orientação situada no próprio passado (12 jovens); na relação passado/presente - seja em torno da compreensão do próprio presente, na explicação das mudanças, em tomar o passado como exemplo para o presente ou para entender a evolução (30 jovens). Finalmente, observa-se que 7 jovens expressam uma orientação temporal mais complexa, ao identificarem a importância de se aprender história para compreender as relações entre passado/presente e futuro.

A segunda parte do instrumento solicitava aos jovens a produção de uma narrativa, partindo-se do pressuposto de que "a narrativa histórica é um sistema de operações mentais que define o campo da consciência histórica" (Rüsen, 2010, p.95). A solicitação aos jovens foi feita a partir da seguinte orientação, seguida da apresentação de fotos das manifestações que foram publicadas em jornais do período.

Em junho de 2013 ocorreram várias manifestações em diferentes cidades brasileiras. Observe e analise as imagens e textos que aparecem nos cartazes. Escreva uma narrativa sobre esses acontecimentos.

A principal finalidade era, tendo como suporte o referencial proposto neste trabalho, responder à problemática - que argumentações os jovens poderiam construir sobre as manifestações a partir de imagens que representavam esses acontecimentos e como, por meio de suas narrativas, eles expressariam significados de orientação temporal? Assim, foram propostas as seguintes imagens: 
Figura 1 - O Estado de S. Paulo, segunda-feira, 17 jun. 2013

Legenda: Dicas: Cartilha diz para manifestante não ser violento e usar tênis confortável para correr.

Figura 2 - Gazeta do Povo, quarta-feira, 19 jun. 2013

Legenda: Saques e van queimada: vandalismo marcou o sexto dia de protesto.

Figura 3 - O Estado de S. Paulo, sexta-feira, 14 jun. 2013

Legenda dos cartazes: "Protesto não é crime" e "Sorria, você está sendo explorado".

Figura 4 - domingo, 16 jun. 2013

Legenda do cartaz: Nossos sonhos valem mais que 20 centavos.

É importante observar que as imagens foram utilizadas como instrumentos para a investigação e não como objeto ou foco principal de análise. ${ }^{5}$

\section{Resultados}

Para análise dos dados buscou-se a referência na Grounded Theory, na perspectiva de Charmaz (2009) e Flick (2004). As categorizações foram construídas em um movimento de mão dupla. De um lado, elas foram inferidas dos resultados obtidos, por meio de um processo analítico em que os conceitos foram identificados e analisados a partir de suas próprias dimensões e propriedades. De outro lado, na esteira do referencial teórico adotado, as categorizações foram afinadas e aprofundadas.

Tabela 4 - Significados atribuídos pelos jovens às manifestações de junho de 2013

\begin{tabular}{l|c}
\hline \multicolumn{1}{c|}{ Significados atribuídos } & Número \\
\hline Forma de luta no passado, presente e futuro & 7 \\
Forma de luta do protagonismo dos jovens pelas mudanças & 8 \\
Forma de luta histórica da população & 5 \\
Forma de luta da população pelos seus direitos e pelas mudanças & 34 \\
Movimento de cidadania & 1 \\
Movimento contra o governo do PT (Partido dos Trabalhadores) & 1 \\
Nem liga para as manifestações & 1 \\
\hline
\end{tabular}

Fonte: as autoras (2014). 
O saldo das narrativas produzidas pelos jovens indica uma adesão às manifestações como um movimento legítimo e justo, e em nenhuma das narrativas apareceu uma rejeição a esse tipo de participação política. A perspectiva da relação presente/passado/futuro apareceu de forma relativamente expressiva, podendo ser exemplificada pela ideia contida nestes trechos:

- Muitos sofreram e muitos sofrerão mas o que importa é a luta que dura dia a dia. O governo sobe a tarifa dos transportes mas nosso salário não sobe. (sem identificação, 18 anos, $3^{\circ}$ ano)

- As manifestações têm significado para o passado, o presente e o futuro do meu país porque vamos saber nossos direitos e correr atrás do que é nosso. $\mathrm{O}$ transporte coletivo, o valor da tarifa está muito caro e ainda precisa ser reajustada para menor ainda. As manifestações vão continuar porque a população é maior que muitos políticos ... A presidente Dilma contratou médicos de Cuba para trabalhar no Brasil, muitas coisas têm que mudar no Brasil, tem muito roubo dos políticos. (André, $17,3^{\circ}$ ano)

Além de serem consideradas legítimas, as manifestações também foram vistas como formas históricas de luta do povo brasileiro, cujo significado na vida da nação é considerado maior do que o de muitos políticos. Ademais, elas representariam uma forma de protagonismo dos jovens na realização das mudanças necessárias ao país:

- Foi uma coisa que mexeu com todo o país. Essas manifestações, na minha opinião, mexeram tanto com o país de uma forma que mobilizou o país todo. Ninguém imaginava que poderia ter a proporção que acabou tendo. Essas manifestações cresceram de uma forma tão grande que em cada estado do Brasil as pessoas reivindicaram uma coisa e mostrou o tamanho do jovem no Brasil. Na minha humilde opinião isso irá ser lembrado por muito tempo e nunca se esquecerão que o jovem tem voz. (William, 16 anos, $3^{\circ}$ ano)

A ênfase nas manifestações como forma de luta para mudança e reivindicação dos direitos predominou em 34 das narrativas produzidas. Cabe ressaltar que, quando os jovens falam em direitos, indicam determinadas carências da vida prática, como transporte público de qualidade, educação, saúde pública e combate à corrupção. Não há nenhuma referência a demandas relacionadas com direito à democracia, liberdade ou participação política, o que leva a 
concluir que, no atual contexto da sociedade brasileira, esses direitos estão acessíveis aos jovens:

- O povo está reivindicando os seus direitos, como cidadãos brasileiros, contra a corrupção, para uma melhoria na saúde, segurança etc. Isso irá refletir no ensino das futuras gerações. Afinal, estamos vivendo um momento histórico de nosso país. Muitos acham que esses protestos não têm validade, mas isso é um pensamento tolo, pois nosso país acordou para a realidade, pena que muitos não saibam protestar e acabam fazendo vandalismo e com isso acabam dando outra cara para as manifestações. Enfim, em minha opinião, as manifestações vão ter muitos retornos bons e nossos filhos vão saber que um dia nosso povo é um povo que corre atrás e faz acontecer. (Luiz Fernando, 16 anos, $3^{\circ}$ ano)

Apesar de as imagens mostradas aos jovens apresentarem evidências da violência policial contra os manifestantes, um dos fatores presentes em todos os dias de manifestações, apenas cinco narrativas fazem referência a esse fato:

- As manifestações que ocorreram em 2013 foram muita violência. Muitos sabiam protestar adequadamente mas muitos não sabiam fazer protestos, queriam levar na grosseria, querendo tudo que viam pela frente, maltratando e machucando muitas pessoas, como os PM ... Daqui para frente vai haver mais protestos sim e vão se repetir as cenas de violência no povo e com as pessoas, ou até coisa pior. (sem identificação)

- Na verdade, boa parte da história tem indícios de manifestações e toda manifestação tem um porquê. No caso das manifestações que ocorreram no Brasil, boa parte dos jovens saíram às ruas para reivindicar os seus direitos e eles pediram coisas relativamente simples para o governo. Apenas o reajuste das passagens do transporte público, mais investimento na saúde e na educação e também que o governo parasse de usar o dinheiro público indevidamente. Como, por exemplo, investir na Copa do Mundo de 2014, enquanto o país inteiro estava precisando de hospitais, escolas e transporte público de qualidade. Como pode um país sediar a Copa do Mundo, um evento tão grandioso, com tanta criminalidade, transporte insuficiente, enquanto estão investindo em coisas banais. Sem contar que, quando ocorreram as manifestações, muitos dos nossos policiais militares abusaram do seu poder e começa- 
ram a atirar e tentar paralisar as manifestações com spray de pimenta, isso é um absurdo. E como nós queremos sediar a Copa sem um treinamento específico dos policiais? Deter jovens por porte de vinagre? Em que país nós vivemos? (Jennifer Souza, 14 anos, $1^{\circ}$ ano)

- As manifestações mostram que o povo está tentando mudar a cara do nosso país, para ter mais direitos porque nosso país só dá direitos para os políticos que roubam dinheiro do povo brasileiro, dinheiro que deveria ser usado para construir mais hospitais, mais escolas, e esses políticos não são presos ou são presos mas conseguem sair muito rápido da cadeia. Isso é uma vergonha para o país. E a polícia deveria proteger o povo que vai para manifestar seus direitos, não, eles batem em quem está ajudando a garantir os direitos deles também, como mostram as imagens dos dias 14/06/13 e 21/06/2013. Acho que essas manifestações vão ajudar muito no futuro do nosso país. (sem identificação)

Finalmente, cabe destacar que, embora no próprio enunciado do instrumento que foi entregue aos jovens constasse indicação para que eles observassem as imagens relativas às manifestações de junho de 2013, somente nove narrativas indicaram uma referência a essas fontes, como se pode observar nestes exemplos:

- Bom, porque o passado já foi muito corrupto e isto está acontecendo no presente, no agora, ainda mais no agora. Pois não podemos mudar o passado, mas podemos mudar o presente e o futuro. Como diz uma das fotos, não era por "20 centavos", mas sim pela dignidade, direitos e outras coisas. Chega de corrupção, nós queremos um novo Brasil, uma nova história e eu acho que as manifestações significam que podemos mudar é só lutarmos por nossos direitos, para um país melhor. (sem identificação)

- No passado, muitas coisas mudaram com a luta do povo e essas manifestações só são uma continuação do que está acontecendo e do que está por vir. Na prática não mudou muita coisa, mas fez com que o povo expressasse seus pensamentos e opiniões. Podemos ver nas imagens que a maioria dos manifestantes são jovens querendo um futuro melhor. E alguns pais querendo mudar o futuro para os filhos, como mostra a imagem do dia 21/06/2013. O povo havia acordado. E começaram a ver que havia muito dinheiro sendo gasto em coisas desneces- 
sárias, e o que é prioridade estava ficando muito para trás. Na minha opinião, na prática, não mudou nada com as manifestações, somente na teoria. E o governo continua rindo de nossa cara e sambando nos nossos bolsos. Mas acho as manifestações de extrema importância, nós povo, somos a maioria, uma hora ou outra "eles" vão ter que ceder. (Juliana, $17,3^{\circ}$ ano)

- Porque as manifestações acabam por ser marco na história do Brasil, como a busca pelos direitos sociais que despertaram de maneira surpreendente o povo brasileiro, sendo a maioria jovens que buscavam melhores condições de educação, saúde e infraestrutura ... Foi o estopim porque já tinha tanta reclamação principalmente do governo pela sua má administração do dinheiro público. Na frase do dia 20/06/2013 fala assim: O GIGANTE ACORDOU, mas logo voltou a dormir com o calmante que os políticos deram na forma de promessas e mal cumpriram algumas e o povo já ficou satisfeito. (Claudio, 16, $3^{\circ}$ ano)

Algumas questões podem ser inferidas, analisando-se a forma pela qual esses jovens interpelaram as imagens propostas. Apesar de tê-las utilizado como referência para justificar suas opiniões, eles o fizeram indicando contradições que se seguiram após as manifestações, como se observa na fala de um jovem: "em minha opinião, na prática não mudou nada ... mas acho as manifestações de extrema importância". Ou "O Gigante Acordou, mas logo voltou a dormir com o calmante que os políticos deram na forma de promessas". Conclui-se que, ao produzirem inferências a partir das fontes, os jovens o fizeram seletiva e criticamente.

\section{CONSIDERAÇÕES FINAIS}

No que diz respeito às manifestações como expressão da relação da consciência histórica dos jovens com a sua vida prática, uma primeira consideração a fazer é que, independentemente de terem ou não participado das manifestações do junho de 2013 ou de optarem ou não pela participação em manifestações, os jovens do caso analisado aprovam, em sua maioria, as manifestações como uma forma legítima de participação política. Essa perspectiva indica uma semelhança entre as manifestações brasileiras e aquelas que vêm ocorrendo em outros países desde 2011, ou seja, uma revolta e recusa às formas de participação 
política tradicionais, nas quais os jovens já não se sentem mais representados. Assim, a ocupação de ruas e praças é uma das características encontradas nesses movimentos, inclusive no Brasil, em que o slogan "Vem pra rua. Vem!" foi amplamente utilizado.

Outro aspecto indiciário da semelhança entre as várias manifestações são os sentimentos de injustiça e insatisfação, que podem ser inferidos das narrativas dos jovens brasileiros e têm estado presentes também nas outras manifestações. É válido afirmar que, em sua quase maioria, os jovens manifestantes brasileiros podem ser considerados "filhos da geração incluída" no consumo e no acesso à informação pela internet. Essa inclusão não tem sido acompanhada, na sociedade brasileira, pelo acesso a direitos como transporte público, saúde e educação pública de qualidade. A esse sentimento pode somar-se uma revolta contra a violência policial que tem transformado as manifestações em verdadeiras praças de guerras, fato recorrente nas manifestações brasileiras.

Por outro lado, as narrativas dos jovens minimizaram referências a reivindicações de cunho econômico, como o direito ao emprego e o combate à crise econômica, corroborando a análise feita por Brant (2014) de que as questões econômicas que deflagraram manifestações em outros países tenham ficado de fora da pauta no Brasil.

$\mathrm{Na}$ análise das narrativas históricas como expressão da consciência histórica dos jovens, no que tange ao significado das manifestações como função de orientação temporal na sua vida prática, algumas considerações merecem destaque. Quando se faz o cotejamento entre o significado que eles dão à aprendizagem histórica e o significado histórico atribuído às manifestações, deduz-se certa contradição. Na grande maioria de narrativas, 34 no total, as manifestações são forma de lutas reivindicatórias por mudanças que fazem parte do passado, do presente e farão parte do futuro do povo brasileiro. No entanto, quando inquiridos sobre o significado da aprendizagem histórica, apenas sete a articularam com a necessidade de se conhecer a relação passado/ presente e futuro, evidenciando uma desarticulação entre o conhecimento histórico aprendido e as demandas ou carências da vida prática.

Essa contradição pode ser indicativa do que Rüsen (2014) chama de modo funcional de atuação da consciência histórica, em que a consciência histórica está embutida na própria realidade social, "nos procedimentos e instituições, 
nos quais os seres humanos recebem seu cunho cultural ou - recorrendo a uma das metáforas prediletas das atuais ciências culturais - nos quais ele é 'construído'” (Rüsen, 2014, p.100). Ao narrarem um acontecimento que vivenciaram num passado próximo, os jovens expressaram sua consciência histórica muito mais a partir de experiências de vida do que a partir da sua articulação com as ideias e métodos da ciência da história. Revelador disso é o fato de que apenas nove jovens recorreram às fontes (imagens) para elaborar argumentações e opiniões. Esses jovens interpelaram e problematizaram as fontes, o que pode ser considerado um modo reflexivo de atuação da consciência histórica em que há um "posicionar-se consciente em relação à experiência do passado" (Rüsen, 2014, p.101).

À guisa de consideração final, conclui-se que a investigação realizada neste estudo exploratório, para além de afinar o instrumento de investigação para futuras pesquisas, permitiu conhecer elementos da consciência histórica dos jovens, bem como fazer uma avaliação preliminar de formas de atuação de sua consciência histórica em relação às demandas da vida prática, o que corrobora investigações como as realizadas por Alves (2011), Fronza (2012), Azambuja (2013) e Souza (2014). Ademais, ao se ouvirem os jovens, é possível inferir que, ao contrário das forças policiais, para quem as manifestações são uma forma de guerra e, por isso, devem ser duramente reprimidas, para os jovens, as manifestações são uma forma de reinventar a política e recriar a sociedade, solidária e libertariamente.

\section{REFERENNCIAS}

ALVES, Ronaldo Cardoso. Aprender história com sentido para vida: consciência histórica em estudantes brasileiros e portugueses. Tese (Doutorado em Educação) Universidade de São Paulo (USP). São Paulo, 2011.

AZAMBUJA, Luciano de. Jovens alunos e aprendizagem histórica: perspectivas e princípios metodológicos a partir do trabalho com a canção popular. Tese (Doutorado em Educação) - Universidade Federal do Paraná (UFPR). Curitiba, 2013.

BARCA, Isabel. Educação Histórica: uma nova área de investigação? In: ARIAS NETO, Miguel (Org.) Dez anos de pesquisa em ensino de história. Londrina, PR: AtritoArt, 2005. p.15-25.

BRANT, João. Um ano depois de junho. Le Monde Diplomatique (Brasil), ano 7, n.83, p.34-35, 2014. 
CARNEIRO, Henrique Soares. Rebeliões e ocupações de 2011. In: OCCUPY. Movimentos de protesto que tomaram as ruas. São Paulo: Boitempo; Carta Maior, 2013. p.7-14.

CECATTO, Adriano. O ensino do uso de imagens na formação de professores de história. Dissertação (Mestrado em História) - Universidade Estadual do Ceará (UEC). Fortaleza, 2013.

CHARMAZ, Kathy. A construção da teoria fundamentada. Trad. Joice Elias Costa, Porto Alegre: Artmed, 2009.

DOSSIÊ Juventude e Educação (org. por Olga Celestina da Silva Durand e Maria Auxiliadora Schmidt). Perspectiva, Revista do Centro de Ciências da Educação, Florianópolis, v.22, n.2, jul./dez. 2004.

DUBET, F.; MARTUCELLI, D. En la escuela: sociología de la experiência escolar. Buenos Aires: Losada, 1998.

FLICK, Uwe. Uma introdução à pesquisa qualitativa. Trad. Sandra Netz. 2.ed. Porto Alegre: Bookman, 2004.

FRONZA, Marcelo. A intersubjetividade e a verdade na aprendizagem histórica de jovens estudantes a partir das histórias em quadrinhos. Tese (Doutorado em Educação) - Universidade Federal do Paraná (UFPR). Curitiba, 2012.

JARDIM, Maria Chaves. Entrevista: A política em xeque. Caros Amigos, São Paulo, ano XVII, n.207, p.24-28, 2014.

LEAL, Fernanda de Moura. Didática da história e imagens: reflexões em torno da consciência histórica em visualidades formativas. Dissertação (Mestrado em História) - Universidade Federal de Goiás (UFG). Goiânia, 2013.

LEE, Peter. Em direção a um conceito de literacia histórica. Educar em Revista - Dossiê Educação Histórica, Curitiba: Ed. UFPR, número especial, 2006.

Fused Horizons? UK Research into students' second-order ideas in history: a perspective from London, 2015. (Texto inédito).

LÖWY, Michael. O transbordo do copo de cólera. O Estado de S. Paulo, Suplemento Aliás, p.14, 13 nov. 2011.

MOIMAZ, Erica Ramos. O uso da imagem no ensino médio: uma avaliação sobre essa contribuição para a aprendizagem dos conteúdos em história. Dissertação (Mestrado em Educação) - Universidade Estadual de Londrina (UEL). Londrina, 2009.

RÜSEN, Jörn. Cultura faz sentido: orientações entre o ontem e o amanhã. Trad. Nelio Schneider. Petrópolis, RJ: Vozes, 2014.

. Narrativa histórica: fundamentos, tipos, razão. In: SCHMIDT, M. A.; BARCA, I.; MARTINS, E. R. Jörn Rüsen e o ensino de história. Trad. Marcelo Fronza. Curitiba: Ed. UFPR, 2010. p.93-108.

- ¿Qué es la cultura histórica? Reflexiones sobre una nueva manera de abordar la historia. [Versão inédita, em espanhol, do original em alemão, em: FÜSS- 
MANN, K.; GRÜTTER, H. T.; RÜSEN, J. (Ed.) (1994). Historische Faszination. Geschichtskulturheute. Keulen, Weimar and Wenen: Böhlau, 1994. p.3-26]. 2009.

RÜSEN, Jörn. Razão Histórica: teoria da história: os fundamentos da ciência histórica.

Trad. Estevão Martins. Brasília: Ed. UnB, 2001.

Teoria da História: uma teoria da história como ciência. Trad. Estevão C. de R. Martins. Curitiba: Ed. UFPR, 2015.

SCHMIDT, Maria A.; BARCA, Isabel. Uma epistemologia da pesquisa em Educação Histórica. In: SCHMIDT, Maria A.; BARCA, Isabel; URBAN, Ana Claudia. Passados possíveis: a Educação Histórica em Debate. Ijuí, RS: Ed. Unijuí, 2014. p.21-39.

SOUZA, Éder Cristiano. Cinema e educação histórica: jovens e sua relação com a história nos filmes. Tese (Doutorado em Educação) $\bigotimes$ Universidade Federal do Paraná (UFPR). Curitiba, 2014.

VIEIRA, Jucilmara Luiza Loos. Cultura histórica e cultura escolar: diálogos entre a iconografia pictórica histórica e o ensino de história. Dissertação (Mestrado em Educação) - Universidade Federal do Paraná (UFPR). Curitiba, 2015.

\section{NOTAS}

${ }^{1} \mathrm{O}$ campo de estudos e pesquisas denominado Educação Histórica vem se desenvolvendo no Brasil, principalmente, na esteira das investigações realizadas pelo grupo de Educação Histórica anglo-saxão e pelo grupo português. Trajetórias destes grupos podem ser encontradas em trabalhos como os de Isabel Barca (2005); Maria Auxiliadora Schmidt e Isabel Barca (2014); Peter Lee (2015).

${ }^{2}$ Uma das pesquisas recentes que contribuíram para elucidar relações entre o conceito de "vida prática" desenvolvido por Jörn Rüsen e suas articulações com a aprendizagem histórica de jovens é a tese de doutorado de Ronaldo Cardoso Alves (2011).

${ }^{3}$ Os conceitos de "jovem", "juventude" e "condição juvenil" foram abordados na perspectiva de autores como François Dubet, Danilo Martucelli e Mario Margulis, entre outros. Ver, principalmente: Dubet \& Martucelli (1998) e Dossiê Juventude e Educação (2004), organizado por Olga Celestina da Silva Durand e Maria Auxiliadora Schmidt.

${ }^{4} \mathrm{O}$ conceito de manifestações de rua foi apropriado de Henrique Soares Carneiro (2013).

${ }^{5}$ Atualmente há uma interessante produção acadêmica acerca das relações entre imagens e ensino de história. O objeto e o objetivo deste estudo exploratório não foi desenvolver esta problemática. Ver, por exemplo, os trabalhos de Erica Ramos Moimaz (2009), Jucilmara Luiza Loos Vieira (2015), Fernanda de Moura Leal (2013) e Adriano Cecatto (2013).

Artigo recebido em 28 de março de 2016. Aprovado em 28 de maio de 2016. 